\title{
Can prophylactic transvaginal cervical cerclage improve pregnancy outcome in patients receiving cervical conization? A meta-analysis
}

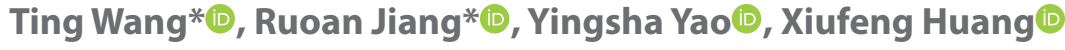 \\ Department of Obstetrics and Gynecology, Women's Hospital Zhejiang University School of Medicine, China \\ ${ }^{*}$ co-first authors
}

\begin{abstract}
Objectives: Cervical conization could increase the risk of cervical insufficiency. This study systematically evaluated the value of prophylactic transvaginal cervical cerclage following cervical conization with regards to pregnancy outcome.

Material and methods: We performed a systematic review of the literature, using Web of Science, and Embase, the published time ranged from the date that database established to December 2019. Pregnant patients, who had a previous history of cervical conization for CIN or early cervical cancer, were enrolled. Two researchers searched these databases and estimated the included studies' quality independently, depending on the same criteria.

Results: Our meta-analysis is incorporate 3560 cases eventually. Meta-analysis showed that when compared to the no-cerclage group, the risk ratio (RR) of preterm birth in the prophylactic transvaginal cervical cerclage group was 1.85 [95\% confidence interval $(\mathrm{Cl}): 1.22-2.80 ; p=0.004$ ]; the RR of premature rupture of membranes was 1.5 (95\% Cl: 1.17-1.93; $p=0.001$ ). Conclusions: The rates of preterm birth were significantly higher in women following cervical conization with transvaginal cerclage than those without cerclage.
\end{abstract}

Key words: cervical conization; prophylactic cervical cerclage; preterm birth; premature rupture of membranes

Ginekologia Polska 2021; 92, 10: 704-713

\section{INTRODUCTION}

The diagnosis rate of cervical intraepithelial neoplasia (CIN) and micro-invasive cervical carcinoma is much higher in recent years because of the wide usage of cervical sampling [1]. In addition, as delayed childbearing becomes a global trend, the proportion of women of reproductive age who are diagnosed with CIN, and early cervical cancer, is gradually increasing.

High grade CIN and micro-invasive cervical carcinoma can be treated with excisional procedures, also referred to as conization. These procedures include cold knife conization, the loop electrosurgical excision procedure (LEEP), and laser conization. The aim of these procedures is to remove a segment of the cervix for histological examination. The women of reproductive age who experienced these treatments may face negative fertility and pregnancy outcomes in the future.

It is currently considered that cervical conization may increase the risk of cervical insufficiency [2]. Some recent studies have revealed that previous cervical conization is associated with an increased risk of second-trimester pregnancy loss [3,4], preterm premature rupture of membranes (PPROM), preterm delivery, and perinatal mortality.

A prospective series of research previously revealed that the detection of a short cervix $(<25 \mathrm{~mm})$ on second-trimester transvaginal ultrasound examination was predictive of an increased risk of preterm birth in women who had experienced conization previously $[5,6]$. It is generally accepted that cervical conization may increase the risk of cervical insufficiency; the role of prophylactic cervical cerclage has not been fully studied in women who have undergone previous cervical conization. The effectiveness of prophylactic transvaginal cervical cerclage remains controversial, and its use is associated with perinatal risks. Therefore, this study used the meta-analysis method to systematically evaluate the value of prophylactic transvaginal cervical cerclage following cervical conization in pregnant outcome, in order to provide evidence-based medical evidence for clinical treatment.

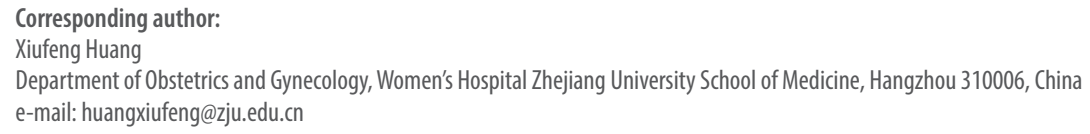




\section{MATERIALS AND METHODS}

\section{Information retrieval}

We searched the database (Web of Science and Embase), setting the published time range from the date that database established to December 2019. The topic term words or free-searching term words used in the database included: cervical conization, co ld knife conization, CKC, loop electrosurgical excision, LEEP, and cervical cerclage.

\section{Inclusion and exclusion criteria Inclusion criteria}

There were three types of inclusion criteria - 1. study type: studies were included in our meta-analysis if they represented a prospective or retrospective and were written in English; 2. research target: patients giving birth after cervical conization, those who received transvaginal cervical cerclage represented the case group, while those who did not receive cerclage represented the control group; 3 . outcome index: studies were included in our meta-analysis if they reported the risk of preterm birth, premature rupture of membranes (PROM), preterm premature rupture of membranes (PPROM), perinatal mortality, or low birth weight.

\section{Exclusion criteria}

Studies were excluded if they were conference papers, reviews, lectures, or abstracts. Studies were also excluded if the full text was not available, or if they did not include the detailed information or enough data. Self-control clinical trials were also excluded, as were studies that included outcomes for twins, or higher-order multiple births; this was because of the association between plurality and preterm birth.

\section{Quality evaluation}

Cochrane risk of bias tool was used to evaluate the quality of incision articles. There were two researchers who searched these databases, estimated the included studies' quality independently, depending on the same criteria. In order to do this, the researchers used self-made data extraction forms, which targeted information relating to patient characteristics, the number of samples, obstetric outcomes, and neonatal outcomes. Subgroup analyses were only performed for cases involving preterm birth at $<34$ weeks, and 34-36 + 6 weeks of gestation.

\section{Statistical analysis}

Meta-analysis was carried out using Review Manager 5.3 software. Our meta-analysis used both fixed-effects and random-effects depending on the heterogeneity. Statistical heterogeneity of results featured in the selected studies was assessed using the chi-squared test, expressed with the 12 index or $p$-value; when $p>0.10$ or $12 \leq 50 \%$, we considered that there was no obvious heterogeneity in the included studies, and the fixed-effect model was used. When heterogeneity was detected, we made intensive efforts to identify a possible explanation. If a reasonable cause was found, then subgroup analysis was performed. Otherwise, a random-effects model was used. Variables are represented by relative risks (RRs); interval estimates are all based on $95 \%$ confidence intervals (95\% Cls). Differences were considered to be statistically significant when $p<0.05$.

\section{RESULTS \\ Information retrieval}

After first-circle database searching, 261 articles were detected. Following reading and screening, we accepted nine studies to be included in our final meta-analysis [7-15]. Figure 1 illustrated the literature screening process.

\section{Basic characteristics and literature quality}

Table 1 and Table 2 demonstrated the basic characteristics of studies included and Figure 2 showed the literature quality. Ultimately, nine studies were included in the final meta-analysis, featuring a total of 3560 patients; 605 women were treated by prophylactic transvaginal cervical cerclage following conization, while 2,955 women were not.

\section{Systematic review}

A risk ratio forest plot showed that the total risk ratio. The total risk ratio for preterm birth was $1.85(p=0.004)$,

Obtain relevant literature through database search $(n=261)$ Web of Science $(n=115)$, Embase $(n=146)$

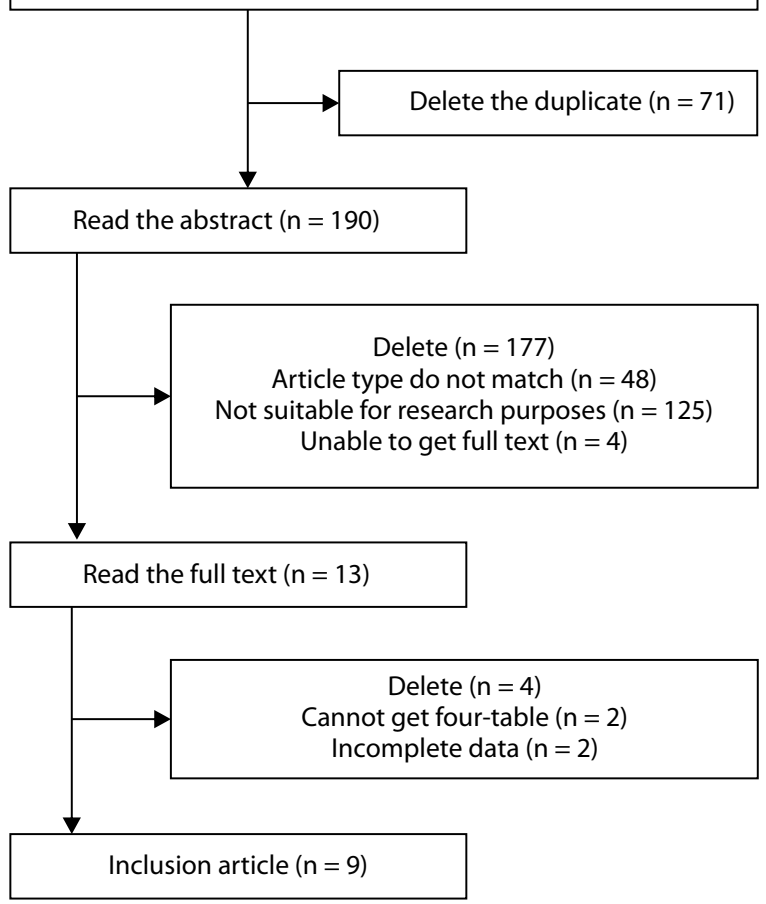

Figure 1. Document screening process and results 
Table 1. Basic characteristics of the studies included in this meta-analysis

\begin{tabular}{|l|c|c|c|c|c|}
\hline Study & Year & Nation & Study design & $\begin{array}{c}\text { Transvaginal prophylactic cerclage specific method } \\
\text { Maternal age } \\
\text { (mean) }\end{array}$ \\
\hline Geum Joon Cho & 2018 & Korea & Retrospective & not clear \\
\hline Harald Zeisler & 1997 & Austria & Retrospective & not clear \\
\hline Ka Hyun Nam & 2010 & Korea & Retrospective & not clear \\
\hline Kei Miyakoshi & 2019 & Japan & Retrospective & not clear \\
\hline Lindsay M. Kindinger & 2016 & Mexico & Retrospective & Monofilament/Braided cerclages \\
\hline Minling Wei & 2018 & China & Retrospective & Transvaginal cervicoisthmic cerclage \\
\hline Mi-Young Shin & 2010 & Korea & Retrospective & not clear \\
\hline Sharon Armarni & 2011 & Israel & Retrospective & not clear \\
\hline Tal Rafaeli-Yehudai & 2014 & Israel & Retrospective & 33.22 \\
\hline
\end{tabular}

while 12 was $71 \%$. The total risk ratio of PROM was $1.5(p=0.001)$, with an 12 value of $47 \%$. The total risk ratio of PPROM was $1.18(p=0.52)$, with an 12 value of $52 \%$.

The results of our meta-analysis are shown in Figures 3-7. The use of prophylactic transvaginal cervical cerclage in women with cervical conization was associated with a significantly higher risk of preterm birth < 37 weeks (RR, 1.85; 95\% $\mathrm{Cl}, 1.22-2.80), 34-36+6$ weeks (RR, 2.75; 95\% Cl, 1.69-4.47) and < 34 weeks (RR, 3.03; 95\% Cl, 1.06-8.67), and PROM (RR, 1.5; 95\% Cl, 1.17-1.93).

Prophylactic transvaginal cervical cerclage, either with and without cerclage, was not significantly associated with the risk of PPROM $(\mathrm{RR}, 1.18 ; 95 \% \mathrm{Cl}, 0.71-1.96)$, low birth weight (RR, $0.63 ; 95 \% \mathrm{Cl}, 0.24-1.67)$, or perinatal mortality (RR, $\mathrm{m} 1.14 ; 95 \% \mathrm{Cl}, 0.23-5.63)$.

\section{Evaluation of publication evaluation}

Funnel plot test results showed that there was no publication bias for preterm birth, PROM, PPROM, low birth weight, and perinatal mortality (Fig. 8).

\section{DISCUSSION}

Cervical conization is a standard treatment for women with high-gradeCIN and micro-invasive carcinoma (Stage 1a1) [16-18]. Women with cervical dysplasia are at an increased baseline risk of preterm birth, and surgical excision confers additional risk $[19,20]$. Pregnant patients, with a history of surgical excision, should therefore be considered as having high risk pregnancies [20]. Currently, more studies have found that conization therapy may have adverse effect on the following pregnancy outcomes, including preterm delivery, perinatal death and lower birth weight [3]. There are several factors that may underline these associations. First, the removal or destruction of a large portion of the collagen that makes up the cervical stromal may reduce tensile strength, thus reducing the mechanical competence of the cervix [21], and ultimately leading to premature dilation of the cervix during pregnancy. Second, excision of tissue and the absence of cervical glands may increase the risk of ascending infection. Third, cervical shortening causes bacteria to enter the uterine cavity from the vagina, thus promoting the migration of bacteria.

In order to prolong pregnancy, surgery remains the mainstay form of therapy. Cervical cerclage is a common method [22]; this method aims to provide mechanical support to the cervix and thereby reduce the risk of preterm birth, thus prolonging the period of gestation in pregnant women with cervical insufficiency $[23,24]$. This procedure was initially described as a purse string suture around the cervix, performed using a vaginal approach. Some studies have indicated that cervical cerclage reduces the risk of preterm birth in women at high risk of preterm birth, and probably reduces the risk of perinatal deaths; furthermore, existing data appear to suggest that this method is more or less effective than other preventative treatments, particularly vaginal progesterone [25]. However, this method can lead to some adverse outcomes [26], including membrane rupture, chorioamnionitis, cervical lacerations, and suture displacement [27]. The incidence of complications varies widely with regards to the timing and indications for cerclage [28]. Overall, there is a low risk of complications with prophylactic cervical cerclage. Some studies have reported that cervical cerclage may increase the risk of preterm birth in women with a cervical length $<25 \mathrm{~mm}$ on ultrasound [29]. There is no consensus on the effect of cervical cerclage on pregnancy outcome following cervical conization. Therefore, in the present study, a systematic review discovered the advantage of prophylactic transvaginal cervical cerclage on pregnant outcome following cervical conization.

A transabdominal cerclage is used as an alternative for women for whom a transvaginal cerclage fails, or for women who have had large portions of their cervix removed during the treatment of oncological conditions [30]. This meta-anal- 


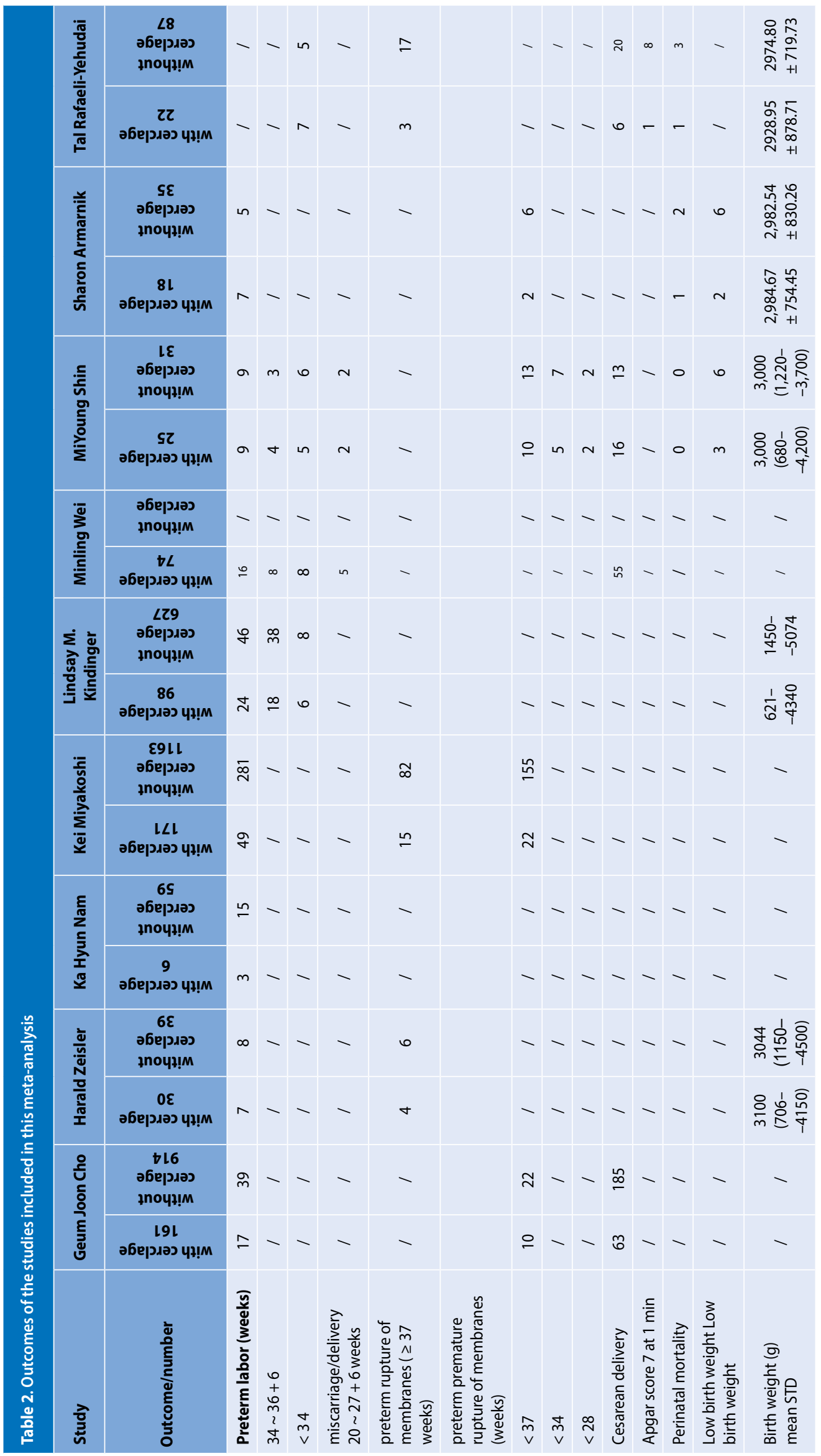



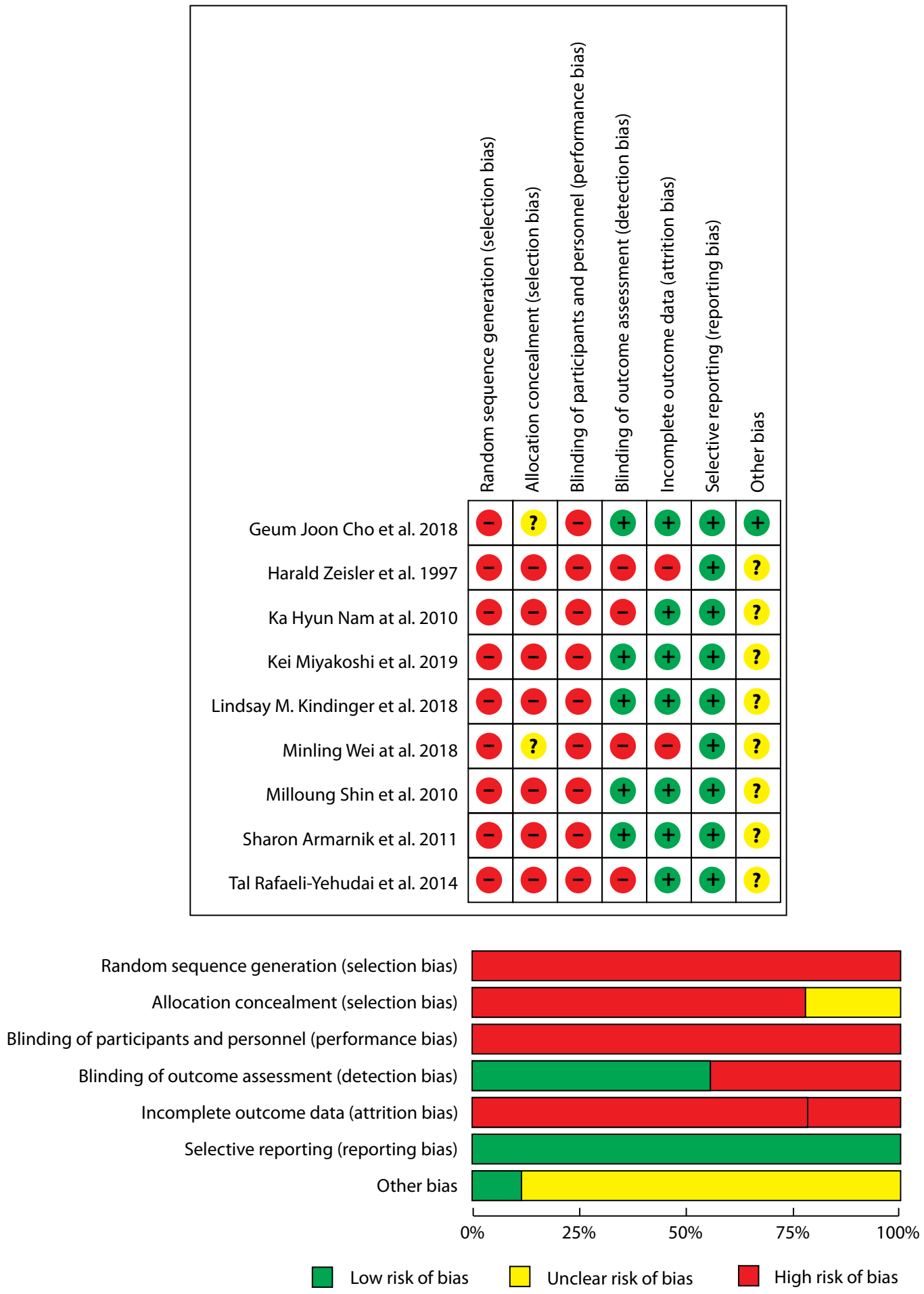

Figure 2. The risk of bias about the inclusion studies

ysis did not include publications relating to transabdominal cervical cerclage. There were two reasons for this. Firstly, when searching the literature, we only retrieved some case reports relating to transabdominal cervical cerclage after cervical conization [31-34]. Secondly, the indication for prophylactic cerclage through the abdomen is slightly different from that of transvaginal cerclage. Patients with cervical weakness who have an extremely short, deformed, or scarred cervix, cannot be adequately managed by prophylactic transvaginal cerclage [35]. There is a difference in the probability of adverse pregnancy outcomes when compared between patients who received transabdominal cerclage, and patients who received cerclage [36]. We retrieved four case reports; the characteristics of these cases are shown in Table 3. 


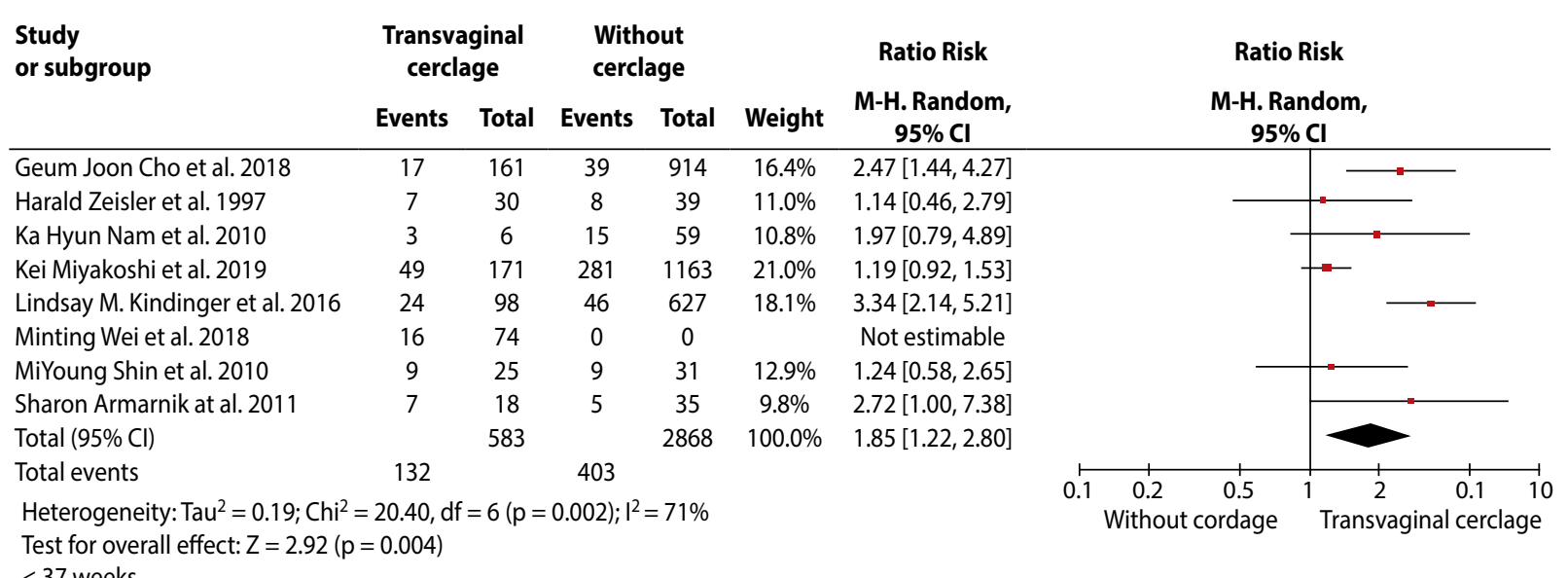

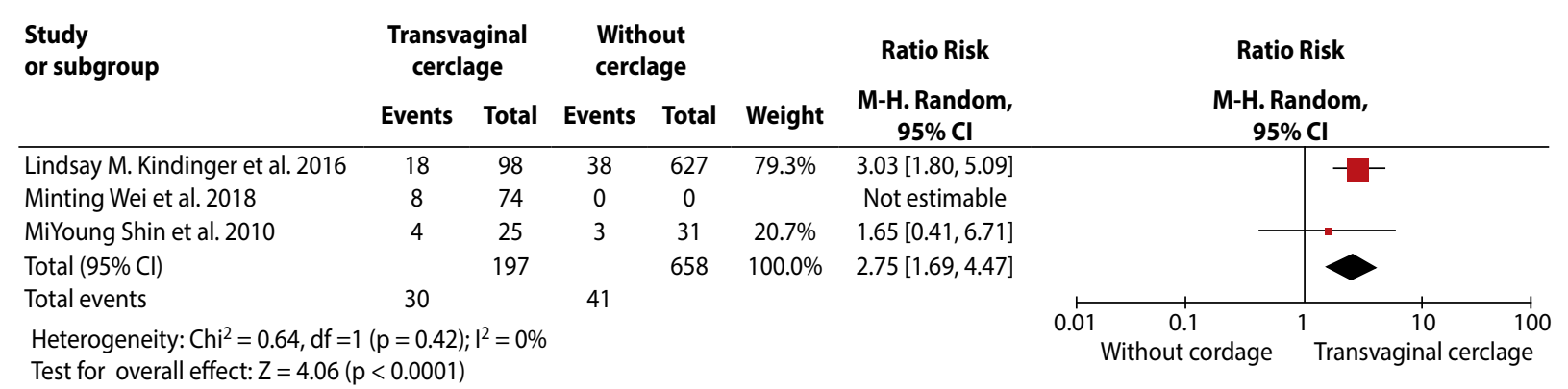

$34-36 \pm 6$ weeks

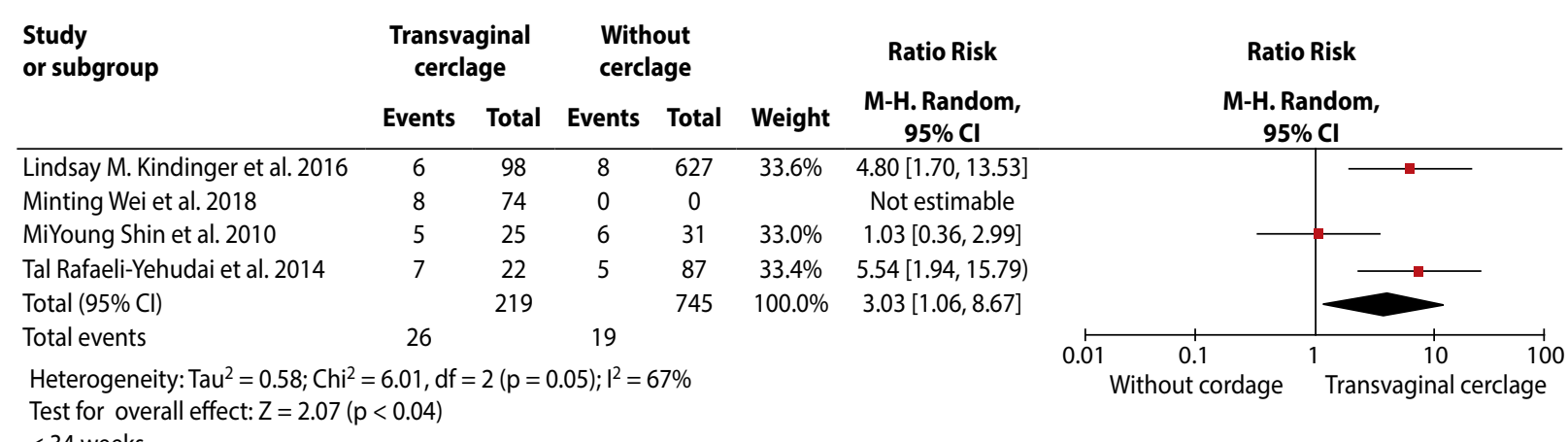

$<34$ weeks

Figure 3. Meta-analysis of preterm birth

We consider that prophylactic transabdominal cerclage is an important treatment modality to improve obstetric prognosis and prevent unexpected complications for those with a history of transvaginal cervical cerclage failure, or multiple cervical cerclage operations. It is likely that the importance of transabdominal cerclage will increase with the development of conservative operations for invasive uterine cervical cancer. In addition, Ioannis Kyvernitakis previously reported that the results of transabdominal cerclage were comparable to those in singleton pregnancies, and that indications for transabdominal cerclage may be justifiable even in multiple gestations [33]. There is only a limited amount of data relating to prophylactic transab- dominal cervical cerclage following cervical conization; further studies are now needed with larger sample sizes.

In order to avoid the significant levels of heterogeneity among different publications relating to pregnancy outcomes, we selected publications for our analysis_using strict criteria. The results were calculated by fixed models due to slight heterogeneity. The results of our meta-analysis showed that there was a large variation between the two groups with regards to the occurrence of preterm birth and PROM. The rates of preterm birth and PROM were significantly higher in women with prophylactic transvaginal cervical cerclage than those without cerclage. However, there was no significant difference in 


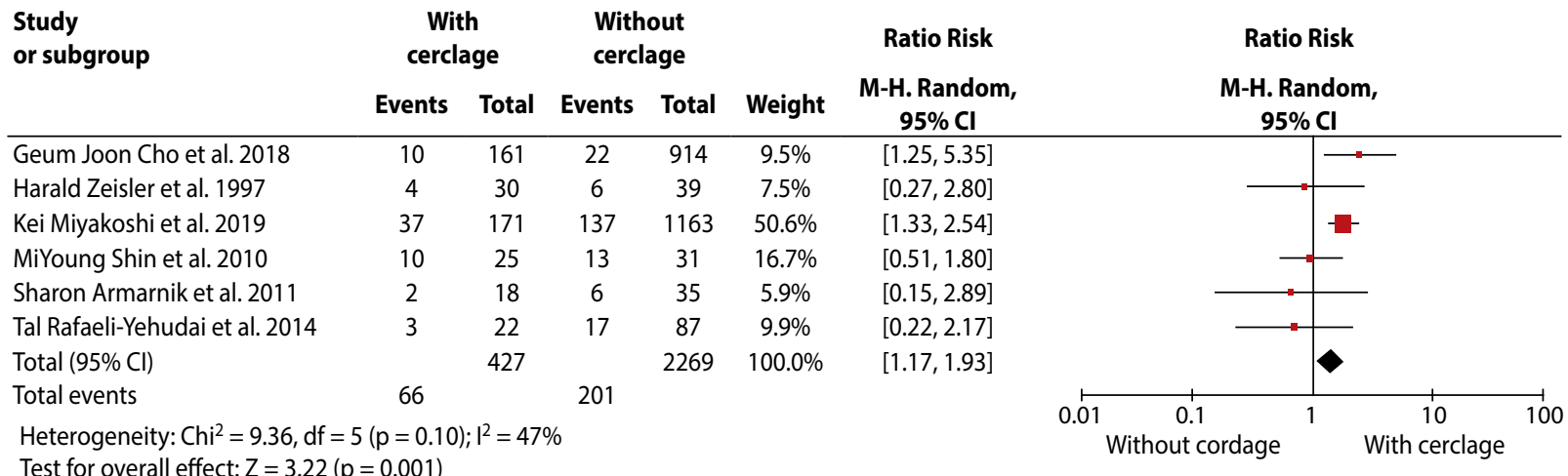

Figure 4. Meta-analysis of premature rupture of membranes (PROM)

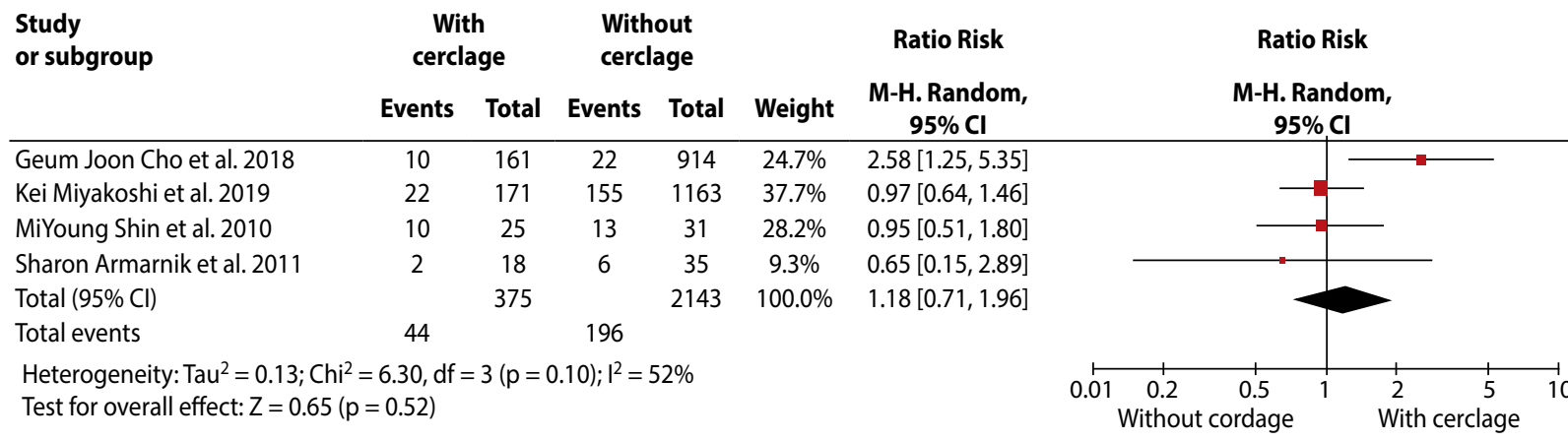

Figure 5. Meta-analysis of preterm premature rupture of membranes (PPROM)

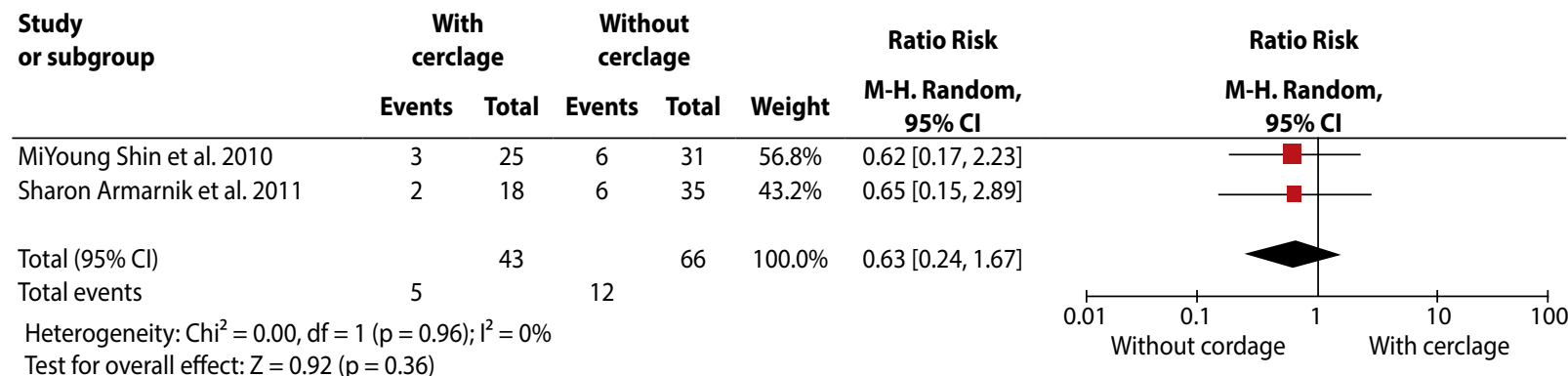

Figure 6. Meta-analysis of low birth weight

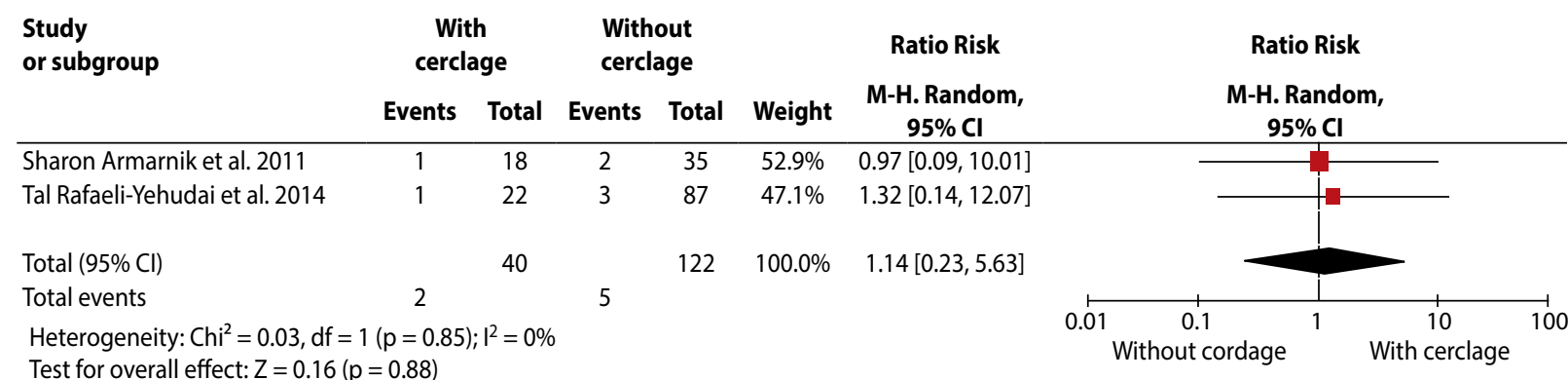

Figure 7. Meta-analysis of perinatal mortality 

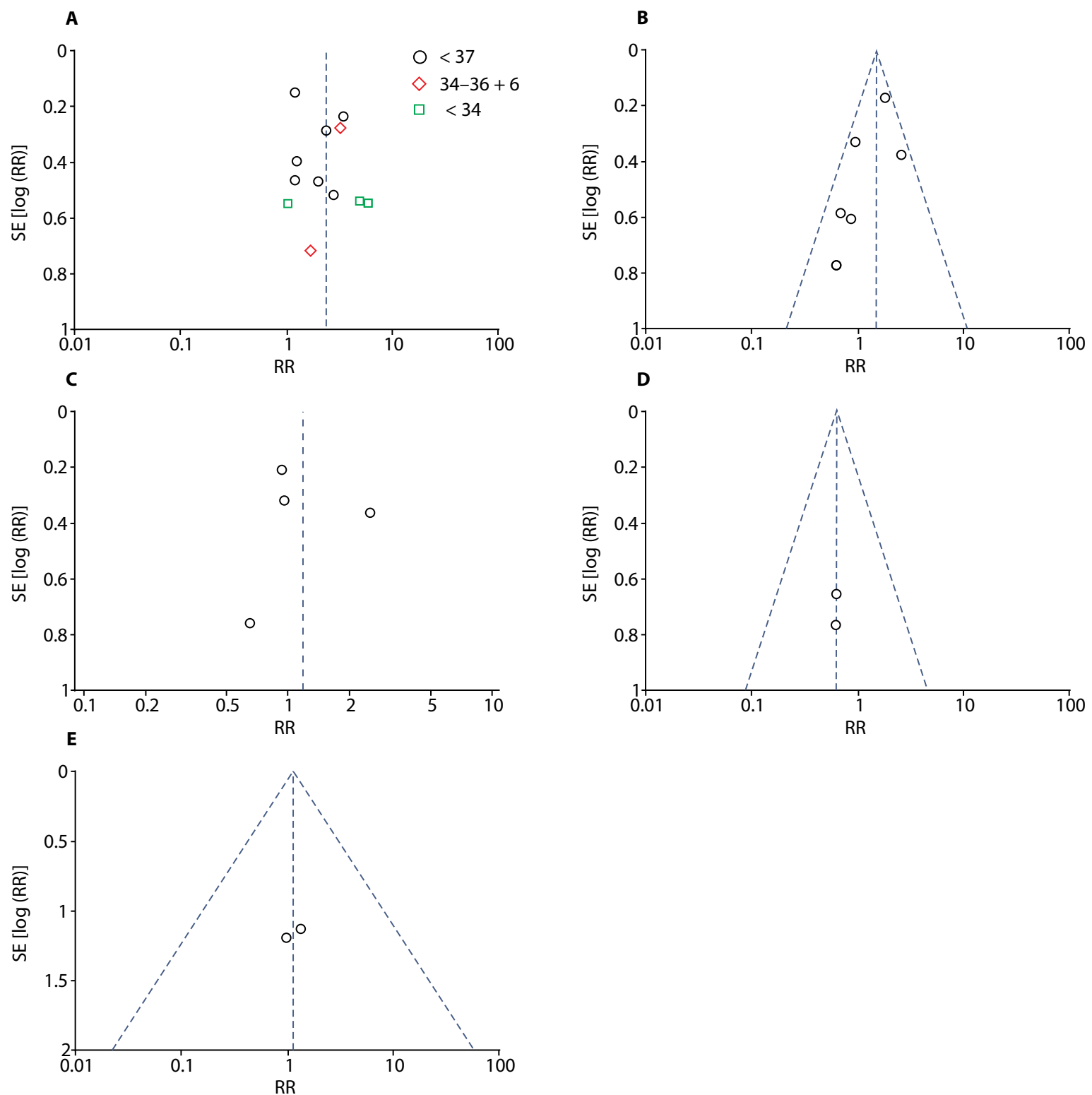

Figure 8. Funnel plot; $\mathrm{A}$ — preterm birth; $\mathrm{B}-\mathrm{PROM} ; \mathrm{C}-\mathrm{PPROM}$; $\mathrm{D}$ - low birth weight; $\mathrm{E}$ - perinatal mortality

the risk of PPROM, low birth weight, and perinatal mortality, when compared between patients with prophylactic transvaginal cervical cerclage than those without cerclage. In most studies, the indication for cerclage operation was not stated in detail. Some of the heterogeneity between studies that we observed during our meta-analysis may have been associated with the different basic characteristic line, including pregnancy time, auxiliary exam level, medical history and whether there was a subjective judgment for cerclage.

This meta-analysis suggested that prophylactic transvaginal cerclage following conization increases the risk of preterm birth and PROM. In France, a history-indicated cerclage is not recommended for women with only a history of conization [31]. In another study, Kaye and Giraldo-Isaza considered that the increasing risk of PROM following cervical cerclage may related to the risk of ascending infection [32, 33].

Thus far, a variety of treatment methods has been used for cervical conization, including electrocautery, cryotherapy, laser ablation, cold knife conization, hot knife conization, and LEEP [36, 37]. Some studies reported that different conization methods have different effects on pregnancy outcomes $[38,39]$. A recent meta-analysis reported that the risk of preterm birth and adverse sequelae in a subsequent pregnancy was increased after any local cervical treatments [40]. Furthermore, The larger the scope of the operation, the more obvious the adverse effect on the following preg- 


\begin{tabular}{|c|c|c|c|c|c|c|c|}
\hline Study & Year & Nation & $\begin{array}{c}\text { Case } \\
\text { number }\end{array}$ & $\begin{array}{l}\text { Conization } \\
\text { method }\end{array}$ & $\begin{array}{l}\text { Cerclage } \\
\text { technique }\end{array}$ & pregnancy outcome & $\begin{array}{l}\text { Neonatal } \\
\text { outcome }\end{array}$ \\
\hline $\begin{array}{l}\text { loannis } \\
\text { Kyvernitakis } \\
\text { [33] }\end{array}$ & 2014 & Germany & 15 (twins) & $\begin{array}{l}\text { Radical Surgical } \\
\text { Conization (15) }\end{array}$ & $\begin{array}{l}\text { Transabdominal } \\
\text { cervicoisthmic } \\
\text { cerclage (14); } \\
\text { Laparoscopic } \\
\text { transabdominal } \\
\text { cervicoisthmic } \\
\text { cerclage (1) }\end{array}$ & $\begin{array}{l}\text { Vaginal bleeding (1); } \\
\text { Preterm labor (1); } \\
\text { PPROM (1) }\end{array}$ & $\begin{array}{l}\text { Alive (26); } \\
\text { perinatal } \\
\text { deaths (3); } \\
\text { stillborn (1) }\end{array}$ \\
\hline M. Besio [31] & 2004 & Chile & 7 (singleton) & $\begin{array}{l}\text { Wide conization (5); } \\
\text { unknow (2) }\end{array}$ & $\begin{array}{l}\text { Transabdominal } \\
\text { cervicoisthmic } \\
\text { cerclage }\end{array}$ & $\begin{array}{l}\text { Chorioamninitis }(2, \text { conization } \\
\text { method unknow) }\end{array}$ & Stillborn (1) \\
\hline $\begin{array}{l}\text { Shinichi Ishioka } \\
\text { [34] }\end{array}$ & 2018 & Japan & $\begin{array}{c}10 \\
\text { (singleton) }\end{array}$ & $\begin{array}{l}\text { Conization twice (3), } \\
\text { conization (2); radical } \\
\text { Surgical Conization } \\
\text { (5) }\end{array}$ & $\begin{array}{l}\text { Transabdominal } \\
\text { cerclage }\end{array}$ & $\begin{array}{l}\text { Miscarriage (4); Second } \\
\text { trimester of pregnancy (2); not } \\
\text { conceive ( } 1 \text { ) }\end{array}$ & Not clear \\
\hline $\begin{array}{l}\text { Mads Riiskjaer } \\
\text { [32] }\end{array}$ & 2012 & Denmark & $\begin{array}{c}11 \\
\text { (singleton) }\end{array}$ & $\begin{array}{l}\text { Two or three previous } \\
\text { conizations or } \\
\text { a cervical amputation }\end{array}$ & $\begin{array}{l}\text { Laparoscopic } \\
\text { abdominal } \\
\text { Cerclage }\end{array}$ & $\begin{array}{l}\text { One woman delivered at } 31 \\
\text { weeks, others had } \\
\text { cesarean section at 36-39 } \\
\text { weeks }\end{array}$ & Not clear \\
\hline
\end{tabular}

nancy outcomes [cold knife conization (CKC) > large loop excision of the transformation zone (LLETZ) > laser ablation (LA)], and was also higher for excision than ablation. The risk of preterm birth increased with the increasing conization depth [40].

The present meta-analysis includes the most recent literature. We used strict criteria, which could ensure the quality of the including published studies. We also calculated Newcastle-Ottawa-Scale NOS in order to determine the quality of the studies included. We also determined publication bias in order to ensure that our results were robust. For strengthening our conclusions, we also adopt meta-regression and in influence analyses.

There are some limitations in this meta-analysis that should be considered. First, the publications included were retrospective studies, and the overall quality of these studies was not high. Secondly, although we applied strict inclusion and exclusion criteria, it was possible that we did not include other biological factors that could have affected pregnancy outcome. Third, our analyses only considered publications that were written in English. Finally, we were not able to sub-divide the conization according to the height of the cervical conization column.

\section{CONCLUSIONS}

In conclusion, our meta-analysis suggested that prophylactic transvaginal cervical cerclage following conization increases the risk of preterm birth and PROM. Further studies, with a larger sample size, should now be performed in order to confirm our findings.

\section{Conflicts of interest}

The authors declare no conflict of interest.

\section{REFERENCES}

1. Prendiville W. The treatment of CIN: what are the risks? Cytopathology. 2009; 20(3): 145-153, doi: 10.1111/j.1365-2303.2009.00669.x, indexed in Pubmed: 19489986

2. Rincon M, Pereira LMR. Ambulatory management of preterm labor. Clin Obstet Gynecol. 2012; 55(3): 756-764, doi: 10.1097/GRF. 0b013e31825c8b4b, indexed in Pubmed: 22828108.

3. Albrechtsen S, Rasmussen S, Thoresen S, et al. Pregnancy outcome in women before and after cervical conisation: population based cohort study. BMJ. 2008; 337: a1343, doi: 10.1136/bmj.a1343, indexed in Pubmed: 18801869.

4. Bjørge T, Skare GB, Bjørge L, et al. Adverse pregnancy outcomes after treatment for cervical intraepithelial neoplasia. Obstet Gynecol. 2016; 128(6): 1265-1273, doi: 10.1097/AOG.0000000000001777, indexed in Pubmed: 27824756.

5. Berghella V, Pereira L, Gariepy A, et al. Prior cone biopsy: prediction of preterm birth by cervical ultrasound. Am J Obstet Gynecol. 2004; 191(4): 1393-1397, doi: 10.1016/j.ajog.2004.06.087, indexed in Pubmed: 15507971.

6. Crane JMG, Delaney T, Hutchens D. Transvaginal ultrasonography in the prediction of preterm birth after treatment for cervical intraepithelial neoplasia. Obstet Gynecol. 2006; 107(1): 37-44, doi: 10.1097/01. AOG.0000192169.44775.76, indexed in Pubmed: 16394037.

7. Armarnik S, Sheiner E, Piura B, et al. Obstetric outcome following cervical conization. Arch Gynecol Obstet. 2011; 283(4): 765-769, doi: 10.1007/s00404-011-1848-3, indexed in Pubmed: 21327802.

8. Cho GJ, Ouh YT, Kim LY, et al. Cerclage is associated with the increased risk of preterm birth in women who had cervical conization. BMC Pregnancy Childbirth. 2018; 18(1): 277, doi: 10.1186/s12884-018-1765-6, indexed in Pubmed: 29970019.

9. Kindinger LM, Kyrgiou M, Maclntyre DA, et al. Preterm Birth Prevention Post-Conization: A Model of Cervical Length Screening with Targeted Cerclage. PLoS One. 2016; 11(11): e0163793, doi: 10.1371/journal. pone.0163793, indexed in Pubmed: 27812088.

10. Miyakoshi K, Itakura A, Abe T, et al. Risk of preterm birth after the excisional surgery for cervical lesions: a propensity-score matching study in Japan. J Matern Fetal Neonatal Med. 2021; 34(6): 845-851, doi: 10.1080/14767058.2019.1619687, indexed in Pubmed: 31092078.

11. Nam KaH, Kwon JaY, Kim YH, et al. Pregnancy outcome after cervical conization: risk factors for preterm delivery and the efficacy of 
prophylactic cerclage. J Gynecol Oncol. 2010; 21(4): 225-229, doi: 10.3802/jgo.2010.21.4.225, indexed in Pubmed: 21278883.

12. Rafaeli-Yehudai $T$, Kessous R, Aricha-Tamir B, et al. The effect of cervical cerclage on pregnancy outcomes in women following conization. J Matern Fetal Neonatal Med. 2014; 27(15): 1594-1597, doi: 10.3109/14767058.2013.871254, indexed in Pubmed: 24289749.

13. Shin MY, Seo ES, Choi SJ, et al. The role of prophylactic cerclage in preventing preterm delivery after electrosurgical conization. J Gynecol Oncol. 2010; 21 (4): 230-236, doi: 10.3802/jgo.2010.21.4.230, indexed in Pubmed: 21278884.

14. Wei M, Jin X, Li TC, et al. A comparison of pregnancy outcome of modified transvaginal cervicoisthmic cerclage performed prior to and during pregnancy. Arch Gynecol Obstet. 2018; 297(3): 645-652, doi: 10.1007/s00404-017-4636-x, indexed in Pubmed: 29302808.

15. Zeisler H, Joura EA, Bancher-Todesca D, et al. Prophylactic cerclage in pregnancy. Effect in women with a history of conization. J Reprod Med. 1997; 42(7): 390-392, indexed in Pubmed: 9252928.

16. Paraskevaidis E, Koliopoulos G, Lolis E, et al. Delivery outcomes following loop electrosurgical excision procedure for microinvasive (FIGO stage IA1) cervical cancer. Gynecol Oncol. 2002; 86(1): 10-13, doi: 10.1006/gyno.2002.6650, indexed in Pubmed: 12079292.

17. Santesso N, Mustafa RA, Schünemann HJ, et al. Guideline Support Group. World Health Organization Guidelines for treatment of cervical intraepithelial neoplasia 2-3 and screen-and-treat strategies to prevent cervical cancer. Int J Gynaecol Obstet. 2016; 132(3): 252-258, doi: 10.1016/j.ijgo.2015.07.038, indexed in Pubmed: 26868062

18. Castle PE, Murokora D, Perez C, et al. Treatment of cervical intraepithelial lesions. Int J Gynaecol Obstet. 2017; 138 Suppl 1: 20-25, doi: 10.1002/ijgo.12191, indexed in Pubmed: 28691333.

19. Kirn V, Geiger P, Riedel C, et al. Cervical conisation and the risk of preterm delivery: a retrospective matched pair analysis of a German cohort. Arch Gynecol Obstet. 2015; 291(3): 599-603, doi: 10.1007/s00404-014-3463-6, indexed in Pubmed: 25234516.

20. Gatta LA, Kuller JA, Rhee EHJ. Pregnancy outcomes following cervical conization or loop electrosurgical excision procedures. Obstet Gynecol Surv. 2017; 72(8): 494-499, doi: 10.1097/OGX.0000000000000468, indexed in Pubmed: 28817166.

21. Cunningham F, Gant N, Leveno K, et al. Williams Obstetrics, 21st Edition. Journal of Midwifery \& Women's Health. 2010; 48(5): 369-369, doi: 10.1016/s1526-9523(03)00291-5.

22. Brown R, Gagnon R, Delisle MF. No. 373-cervical insufficiency and cervical cerclage. J Obstet Gynaecol Can. 2019; 41(2): 233-247, doi: 10.1016/j.jogc.2018.08.009, indexed in Pubmed: 30638557.

23. Chen Q, Chen G, Li N. Clinical effect of emergency cervical cerclage and elective cervical cerclage on pregnancy outcome in the cervical-incompetent pregnant women. Arch Gynecol Obstet. 2018; 297(2): 401-407, doi: 10.1007/s00404-017-4602-7, indexed in Pubmed: 29222640.

24. Liu Y, Ke Z, Liao W, et al. Pregnancy outcomes and superiorities of prophylactic cervical cerclage and therapeutic cervical cerclage in cervical insufficiency pregnant women. Arch Gynecol Obstet. 2018; 297(6): 1503-1508, doi: 10.1007/s00404-018-4766-9, indexed in Pubmed: 29627847

25. Ades A, Hawkins DP. Laparoscopic transabdominal cerclage and subsequent pregnancy outcomes when left in situ. Obstet Gynecol. 2019; 133(6): 1195-1198, doi: 10.1097/AOG.0000000000003263, indexed in Pubmed: 31135734.
26. Alfirevic Z, Stampalija T, Medley N, et al. Cervical stitch (cerclage) for preventing preterm birth in singleton pregnancy. Cochrane Database Syst Rev. 2012; 6(4):CD008991, doi: 10.1002/14651858.CD008991.pub2, indexed in Pubmed: 22513970.

27. Kassanos D, Salamalekis E, Vitoratos N, et al. The value of transvagina ultrasonography in diagnosis and management of cervical incompetence. Clin Exp Obstet Gynecol. 2001; 28(4): 266-268, indexed in Pubmed: 11838756.

28. Mitra A, Kindinger $L$, Kalliala I, et al. Obstetric complications after treatment of cervical intraepithelial neoplasia. Br J Hosp Med (Lond). 2016; 77(8): C124-C127, doi: 10.12968/hmed.2016.77.8.C124, indexed in Pubmed: 27487072.

29. Final report of the Medical Research Council/Royal College of Obstetricians and Gynaecologists multicentre randomised trial of cervical cerclage. MRC/RCOG Working Party on Cervical Cerclage. Br J Obstet Gynaecol. 1993; 100(6): 516-523, doi: 10.1111/j.1471-0528.1993. tb15300.x, indexed in Pubmed: 8334085.

30. Althuisius SM, Dekker GA, Hummel P, et al. Final results of the Cervical Incompetence Prevention Randomized Cerclage Trial (CIPRACT): therapeutic cerclage with bed rest versus bed rest alone. Am J Obstet Gynecol. 2001; 185(5): 1106-1112, doi: 10.1067/mob.2001.118655, indexed in Pubmed: 11717642

31. Sentilhes L, Sénat MV, Ancel PY, et al. Prevention of spontaneous preterm birth: Guidelines for clinical practice from the French College of Gynaecologists and Obstetricians (CNGOF). Eur J Obstet Gynecol Reprod Biol. 2017; 210: 217-224, doi: 10.1016/j.ejogrb.2016.12.035, indexed in Pubmed: 28068594.

32. Kaye $D$, Kaye D. Risk factors for preterm premature rupture of membranes at Mulago Hospital, Kampala. East Afr Med J. 2001; 78(2):65-69, indexed in Pubmed: 11682948.

33. Giraldo-Isaza MA, Berghella V. Cervical cerclage and preterm PROM. Clin Obstet Gynecol. 2011; 54(2): 313-320, doi: 10.1097/GRF. 0b013e318217d530, indexed in Pubmed: 21508701.

34. Joung EJ, Go EB, Kwack JY, et al. Successful term delivery cases of trans-abdominal cervicoisthmic cerclage performed at more than 18 weeks of gestation. Obstet Gynecol Sci. 2016; 59(4): 319-322, doi: 10.5468/ogs.2016.59.4.319, indexed in Pubmed: 27462601.

35. Shennan A. A multicentre randomised controlled trial of transabdominal versus transvaginal cervical cerclage. http://isrctn.org/>. , doi: 10.1186/isrctn33404560.

36. Martin-Hirsch PL, Paraskevaidis E, Kitchener H. Surgery for cervical intraepithelial neoplasia. Cochrane Database Syst Rev. 2000(2): CD001318, doi: 10.1002/14651858.CD001318, indexed in Pubmed: 10796771.

37. Kigure K, Nakamura K, Kitahara Y, et al. An electrical scalpel conization versus Shimodaira-Taniguchi conization procedure for cervical intraepithelial neoplasia. Medicine (Baltimore). 2018; 97(41): e12640, doi: 10.1097/MD.0000000000012640, indexed in Pubmed: 30313051.

38. Guo HJ, Guo RX, Liu YL. Effects of loop electrosurgical excision procedure or cold knife conization on pregnancy outcomes. Eur J Gynaecol Oncol. 2013; 34(1): 79-82, indexed in Pubmed: 23590007.

39. Schwarz TM, Kolben T, Gallwas J, et al. Comparison of two surgical methods for the treatment of CIN: classical LLETZ (large-loop excision of the transformation zone) versus isolated resection of the colposcopic apparent lesion - study protocol for a randomized controlled trial. Trials. 2015; 16: 225, doi: 10.1186/s13063-015-0736-8, indexed in Pubmed: 26002493.

40. Kyrgiou M, Athanasiou A, Kalliala IEJ, et al. Obstetric outcomes after conservative treatment for cervical intraepithelial lesions and early invasive disease. Cochrane Database Syst Rev. 2017; 11: CD012847, doi: 10.1002/14651858.CD012847, indexed in Pubmed: 29095502 